\title{
Delirium in the intensive care unit
}

\author{
Jun Gwon Choi
}

Department of Anesthesiology and Pain Medicine, Ilsan Hospital, Dongguk University Medical Center, Goyang, Korea

Delirium is a serious complication that commonly occurs in critically ill patients in the intensive care unit (ICU). Delirium is frequently unrecognized or missed despite its high incidence and prevalence, and leads to poor clinical outcomes and an increased cost by increasing morbidity, mortality, and hospital and ICU length of stay. Although its pathophysiology is poorly understood, numerous risk factors for delirium have been suggested. To improve clinical outcomes, it is crucial to perform preventive measures against delirium, to detect delirium early using valid and reliable screening tools, and to treat the underlying causes or hazard symptoms of delirium in a timely manner. (Korean J Anesthesiol 2013; 65: 195-202)

Key Words: Delirium, Intensive care unit, Outcome.

\section{Introduction}

Critically ill patients in the intensive care unit (ICU) are prone to disturbances of mentation due to various distressing factors, such as medical illness at admission, pain and anxiety caused by surgery, other invasive procedures, and mechanical ventilation, hypotension, hypoxia, metabolic disturbances, restraints, and environmental factors (e.g., light and noise) that interrupt the normal sleep cycle. Physicians and other caregivers in the ICU usually notice agitation as a consequence whereas patients with hypoactive delirium, which is a more frequent delirium subtype and is characterized by diminished mentality or a lethargic feature, remain unnoticed [1-5].

Undesirable outcomes in terms of morbidity, mortality, hospital or ICU length of stay (LOS), and cost burden have been reported, which are associated with under-sedation usually related to untreated pain, over-sedation, and development of delirium [6-29]. Pain, agitation, and delirium are closely interrelated because agitation may be caused by the underlying pain, or inadequate sedation, or may be a symptom of delirium. Delirium is an independent predictor of higher mortality and longer hospital LOS and is associated with fewer ventilator free days and long-term cognitive impairment [6-15]. The ICU sedation paradigm is now shifting to strategies that ensure lighter sedation with a smaller dose and shorter exposure to sedative drugs, while guaranteeing patient comfort and safety, due to increasing recognition of the negative outcomes described above.

Numerous risk factors for delirium have been suggested; these may be modifiable through preventive measures, or non-modifiable. Identifying risk factors at ICU admission, conducting preventive measures against delirium, assessing pain, sedation, and delirium using valid and reliable tools, and

Received: June 12, 2013. Accepted: July 16, 2013.

Corresponding author: Jun Gwon Choi, M.D., Department of Anesthesiology and Pain Medicine, Ilsan Hospital, Dongguk University Medical Center, 814, Siksa-dong, Ilsandong-gu, Goyang 411-773, Korea. Tel: 82-31-961-7873, Fax: 82-31-961-7864, E-mail: cjanes@dumc.or.kr

(c) This is an open-access article distributed under the terms of the Creative Commons Attribution Non-Commercial License (http:// creativecommons.org/licenses/by-nc/3.0/), which permits unrestricted non-commercial use, distribution, and reproduction in any medium, provided the original work is properly cited. 
treating the underlying causes and/or symptoms of delirium will improve the clinical outcomes. The Society of Critical Care Medicine recently issued clinical practice guidelines for the management of pain, agitation, and delirium in adult ICU patients (the 2013 Society of Critical Care Medicine Pain Agitation Delirium [SCCM PAD] guidelines) [30]. Here, we review the epidemiology and management of ICU-related delirium and ICU sedation, which are based on the guidelines.

\section{Definition}

Delirium is a cognitive disturbance with an acute onset or fluctuating clinical courses. According to the Diagnostic and Statistical Manual of Mental Disorders (DSM) IV by the American Psychiatric Association [31], the diagnostic criteria for delirium due to a general medical condition are: A. a disturbance of consciousness (i.e., reduced clarity of awareness of the environment) with reduced ability to focus, sustain, or shift attention; B. a change in cognition (e.g., memory deficit, disorientation, and language disturbance) or the development of a perceptual disturbance that is not better accounted for by a preexisting, established, or evolving dementia; C. the disturbance develops over a short time (usually hours to days) and tends to fluctuate during the course of the day; D. there must be evidence from the history, physical examination, or laboratory findings that the cognitive disturbance is the direct physiologic consequence of a general medical condition.

Delirium is classified into three subtypes: hyperactive, hypoactive, and mixed [1]. Patients with the hyperactive form show agitated, sometimes aggressive, behavior due to increased psychomotor activity. Those with hypoactive delirium show reduced alertness or lethargy due to psychomotor hypoactivity. The mixed type is characterized by alternating features between the two types. Although the hyperactive form is readily recognized and appears to be common, the other two forms have been shown to be more common in hospitalized geriatric or ICU patients [2-4,32-34]. Reports [2,4,5] that the hypoactive form is more common in the elderly and is associated with worse prognosis, but may be easily missed, underscore the importance of regular screening of the level of sedation and delirium using valid and reliable tools.

\section{Incidence and Risk Factors}

The high incidence and prevalence of delirium in the ICU have been investigated. In the multicenter study by Van Rompaey et al. [35], the overall incidence of delirium in the ICU was found to be $30 \%$, whereas Thomason et al. [6] reported the incidence to be almost 50\% in non-ventilated medical ICU (MICU) patients. In an international multicenter study involving 11 countries, the prevalence of delirium was $32.3 \%$ [36]. Mechanically ventilated patients demonstrated a much higher incidence or prevalence of $\sim 60-80 \%[13,32-34,37,38]$.

Identifying risk factors for delirium at ICU admission is the first step in improving the outcomes of delirium by prevention and early detection. Numerous risk factors have been identified and suggested, most from outside the ICU. Inouye [39] proposed predisposing and precipitating factors as risk factors for delirium. Predisposing factors are related to patient characteristics and are difficult to modify. They include age $\geq 65$ years, male sex, dementia, cognitive impairment, history of delirium, depression, immobility, sensory impairment, dehydration, malnutrition, alcohol abuse, treatment with psychoactive and anticholinergic drugs, and coexisting medical conditions. Precipitating factors act as triggering factors for delirium, some of which can be modified through preventive measures. They include sedative hypnotics, narcotics, anticholinergic drugs, treatment with multiple drugs, alcohol or drug withdrawal, primary neurologic diseases, intercurrent illnesses (e.g., infections, hypoxia, shock, and metabolic derangement), type of surgery (e.g., orthopedic surgery and cardiac surgery), admission to ICU, use of physical restraints, bladder catheter, and multiple procedures, pain, emotional stress, and prolonged sleep deprivation.

In a large cohort study in the surgical ICU (SICU) and MICU, Ouimet et al. [40] reported that delirium occurred in $\sim 30 \%$ of critically ill patients and was associated with a history of hypertension and alcoholism, higher Acute Physiology and Chronic Health Evaluation (APACHE) scores, and clinical effects of sedative and analgesic drugs. Age was not associated with delirium in the ICU, a finding also reported by other investigators $[8,35,41]$, but contrary to the suggestion of Inouye [39]. Dubois et al. [41] suggested that risk factors for delirium outside the ICU may not be applicable to critically ill patients. In a prospective multicenter cohort study, Van Rompaey et al. [35] divided risk factors into two predisposing domains (patients' characteristics and chronic pathology) and two precipitating domains (acute illness and environmental factors) and reported that the incidence of delirium was $30 \%$ and the risk factors identified in a multivariate analysis were the use of more than three units of alcohol each day, a predisposing cognitive impairment, more than three infusions, an admission for internal medicine, an endotracheal tube or tracheostomy, no visible daylight, isolation, and no visitors.

Regarding surgery, surgical blood loss, hematocrit $(<30 \%)$, and transfused blood number during the intraoperative period have been suggested to be risk factors for postoperative delirium $[42,43]$. ICU practitioners should consider intraoperative events that may contribute to delirium when identifying the risk factors in patients admitted to the ICU postoperatively.

The 2013 SCCM PAD guidelines [30] state that preexisting 
dementia, history of hypertension and/or alcoholism, and a high severity of illness at admission are baseline risk factors for delirium in the ICU and coma is an independent risk factor for delirium in the ICU. They also state that use of benzodiazepines may be a risk factor whereas the data regarding use of opioids are conflicting.

\section{Detection}

A high incidence and related poor outcomes of delirium have necessitated the development of valid and reliable tools for its diagnosis in addition to thorough history-taking, physical examination, and evaluation of laboratory parameters. Devlin et al. [44] compared six delirium assessment tools; i.e., the Cognitive Test for Delirium, abbreviated CTD, the confusion assessment method for the ICU (CAM-ICU), Intensive Care Delirium Screening Checklist (ICDSC), Delirium Detection Score (DDS), and the Neelon and Champagne Confusion Scale (NEECHAM scale), and emphasized that clinicians should consider the differences among these tools before adopting them (e.g., specific components, ability to identify hypoactive delirium, ability to be used in patients with a compromised level of consciousness, and the ease of use). They also reported that the tools do not measure the severity of delirium or predict patient outcome. The 2013 SCCM PAD guidelines [30] recommend the routine monitoring of pain, agitation, and delirium upon ICU admission. As the most valid and reliable tools for assessment of delirium, the CAM-ICU and ICDSC are recommended.

As described above, delirium is multifactorial, fluctuating over the clinical course and hypoactive and mixed delirium are more common than the hyperactive form. Additionally, intubated critically ill patients cannot respond verbally. Considering these circumstances, time-consuming effort is required to detect delirium. Fortunately, validated tools such as the CAM-ICU and ICDSC facilitate detection of delirium by ICU caregivers at the bedside.

The CAM-ICU is widely used by physicians and other nonpsychiatrist caregivers at the ICU bedside and is useful for nonverbal ICU patients such as those who are intubated $[45,46]$. The CAM-ICU has shown high sensitivity (80-100\%), specificity (90-100\%), and interrater reliability [32,47], although van Eijk et al. [48] reported that routine use of the CAM-ICU by ICU nurses resulted in a lower sensitivity. The CAM-ICU assesses four key features: 1) acute onset or fluctuating course; 2) inattention; 3 ) disorganized thinking; and 4) altered level of consciousness. If 1) and 2) are present and one of either 3) or 4) is present, the CAMICU is positive for delirium. The ICDSC is easily applicable even to patients with compromised communication. It assesses eight features: 1) altered level of consciousness; 2) inattention; 3) disorientation; 4) hallucinations, delusions, or psychosis; 5) psychomotor agitation or retardation; 6) inappropriate speech or mood; 7) sleep/wake cycle disturbance; and 8) symptom fluctuation over $24 \mathrm{~h}$. Each item is scored as 0 (absent) or 1 (present). A score $\geq 4$ is positive for delirium [49]. Compared with the ICDSC, the CAM-ICU has a greater risk of a false positive result when a patient has a compromised level of consciousness because the CAM-ICU requires responses to some questions about inattention and disorganized thinking [44].

\section{ICU Sedation}

Many critically ill patients are likely to experience pain and anxiety due to medical illness, mechanical ventilation, wound dressing, moving in a bed, and invasive procedures such as surgery. The incidence of significant pain in the ICU is $\geq 50 \%$ [50,51]. Pain frequently acts as the causative factor of undersedation usually accompanied by agitation or anxiety; untreated or inadequately treated pain can lead to serious adverse consequences [25-29]. Deep, prolonged sedation has also been associated with poor clinical outcomes, including a longer duration of mechanical ventilation and hospital or ICU LOS, and a higher mortality rate [16-24]. The use of sedatives or opioids is a known risk factor for the development of delirium [24,38,41,52-56]. Growing recognition of these undesirable clinical outcomes associated with under-and over-sedation and the use of sedatives and opioids is changing the ICU sedation paradigm. Novel or reemerging strategies now in use consist of adopting valid and reliable methods of assessing pain and the level of sedation routinely, providing adequate analgesia first, if indicated, avoiding unwanted deep levels of sedation, and minimizing the use of sedatives. These strategies have many favorable outcomes such as a longer duration free of mechanical ventilation, shorter ICU LOS, and a decreased incidence of comorbidities such as delirium [17-19,57-71]. Remifentanil has an ideal context-sensitive half time, rapid onset and offset, and is not dependent on organ metabolism; thus it is used widely for ICU sedation. Remifentanil-based analgo-sedation demonstrated a shorter duration of mechanical ventilation, shorter ICU LOS, and reduced cost [69-71]. The 2013 SCCM PAD guidelines [30] recommend daily interruption of sedation or protocolized sedation to maintain a level of light sedation in mechanically ventilated patients. Additionally, the guidelines recommend use of an interdisciplinary team approach that includes provider education, preprinted and/or computerized protocols and order forms, and quality ICU rounds checklists to facilitate the use of PAD management guidelines or protocols in the adult ICU. They also suggest analgo-sedation or analgesiafirst sedation in mechanically ventilated patients.

Which drugs should we use to attain the goals of ICU sedation described above? Many reports suggest that the use of 
benzodiazepines is related to poor outcomes such as development of delirium, prolonged mechanical ventilation, and longer ICU LOS [24,38,41,52-54], although these agents are widely used to provide anxiolysis and amnesia, control seizure, or treat alcohol or benzodiazepine withdrawal. Opioids have shown conflicting data [38,41,54-56], and Pandharipande et al. [38] speculated that whether the effects of opioids are beneficial or deliriogenic depends on their induction of adequate analgesia without a deeper level of sedation.

The beneficial effects of dexmedetomidine have prompted researchers to investigate the associated outcomes. The use of dexmedetomidine is associated with favorable outcomes, including a shorter duration of mechanical ventilation, shorter ICU LOS, and less brain dysfunction such as delirium or coma compared with benzodiazepines [52,53,72-74].

Despite the dearth of data, propofol may be associated with fewer ventilator days and a shorter ICU LOS than benzodiazepines $[75,76]$.

The 2013 SCCM PAD guidelines [30] suggest nonbenzodiazepine-based sedation, such as with propofol or dexmedetomidine, to improve the clinical outcomes in mechanically ventilated patients.

To provide adequate sedation, routine assessment of pain and the depth of sedation at the bedside is essential. The 2013 SCCM PAD guidelines [30] recommend the Behavioral Pain Scale (BPS) and Critical-care Pain Observation Tool (CPOT) for adult ICU patients who cannot self-report and the Richmond Agitation-Sedation Scale (RASS) and Sedation-Agitation Scale (SAS) in mechanically ventilated patients as the most valid and reliable tools. The guidelines also suggest the use of objective measures of brain function (e.g., auditory evoked potentials, bispectral index, Narcotrend Index, Patient State Index, or state entropy) in adult ICU patients receiving neuromuscular blocking agents.

\section{Prevention}

Methods for the prevention of delirium are categorized into nonpharmacologic interventions of modifiable risk factors and pharmacologic interventions. Few clinical trials have investigated nonpharmacologic delirium prevention in ICU patients, although some favorable data exist for non-ICU patients [77,78]. Inouye et al. [78] conducted nonpharmacologic intervention to prevent delirium in hospitalized older patients and found significant reductions in the incidence and duration but not the severity of delirium. This strategy involves management of six risk factors: 1) early mobilization protocol for immobility; 2) sleep enhancement protocol and nonpharmacologic sleep protocol for sleep deprivation; 3) orientation protocol and cognitively stimulating activities for cognitive impairment; 4) visual aids for visual impairment; 5) hearing aids for hearing impairment; and 6) dehydration protocol for dehydration.

Regarding prevention in the ICU, Colombo et al. [79] reported that reorientation strategies and environmental, acoustic, and visual stimulation reduced the occurrence of delirium, and Schweickert et al. [80] and Needham et al. [81] showed that early mobilization reduced the incidence of delirium.

The ABCDE (awakening and breathing coordination, delirium monitoring, and exercise/early mobility) bundle approach has been proposed to mitigate ICU-acquired delirium and weakness, which are predictive of poor outcomes in mechanically ventilated and/or sedated ICU patients [82-84]. This approach incorporates evidence-based strategies into daily clinical practice [82]. This protocol-based strategy involves a pass or fail evaluation during continuous monitoring of sedation and delirium. Spontaneous awakening trials are paired with spontaneous breathing trials followed by extubation, and exercise thereafter. If any trials fail, a lighter level of sedation is provided by decreasing or titrating the dose. After reassessment of sedation and delirium, retrials are performed [82]. This bundle approach may be a promising option in clinical practice for the management of critically ill patients.

The 2013 SCCM PAD guidelines [30] recommend early mobilization, but not a pharmacologic or a combined pharmacologic and nonpharmacologic prevention prototocol to reduce the incidence and duration of delirium. The guidelines also recommend promoting sleep by optimizing patients' environments, using strategies to control light and noise, clustering patient care activities, and decreasing stimuli at night. The guidelines do not suggest either haloperidol or atypical antipsychotics to prevent delirium in these patients, although some reports demonstrated that prophylactic intravenous haloperidol after noncardiac surgery, and risperidone administration after cardiac surgery with cardiopulmonary bypass reduced the incidence of postoperative delirium in the ICU $[85,86]$.

\section{Treatment}

The principles of delirium treatment are the correction of underlying causative factors and symptomatic treatment using haloperidol or atypical antipsychotics. Maximizing the safety of the environment and providing psychosocial support are also important in delirious patients.

Haloperidol, a first-generation antipsychotic, has been the treatment of choice for symptomatic ICU delirium [87]. It inhibits hallucination, delusions, and unstructured thoughts and shows some sedative effect [87]. Its antidopaminergic activity can exert extrapyramidal symptoms and poses a risk to delirious patients with Parkinson's disease [87]. When delirium is associated with alcohol, benzodiazepines, and barbiturates withdrawal, benzodiazepines are the treatment of choice [88]. 
Second-generation antipsychotics, commonly known as atypical antipsychotics, include risperidone (Risperdal), olanzapine (Zyprexa), and quetiapine (Seroquel). They are equally effective in treating delirium and have fewer side effects than haloperidol $[89,90]$. Atypical antipsychotics may reduce the duration of delirium in the ICU according to the 2013 SCCM PAD guidelines [30].

Torsades de pointes is a fatal complication associated with the use of haloperidol and atypical antipsychotics [91-96]. The 2013 SCCM PAD guidelines [30] do not suggest use of these drugs in patients with baseline prolongation of the QT interval, patients receiving concomitant medications known to prolong the QT interval, or patients with a history of this arrhythmia.

Dexmedetomidine has shown less delirium in mechanically ventilated patients requiring sedation than benzodiazepines $[13,52,53,72]$. The 2013 SCCM PAD guidelines [30] suggest its use rather than benzodiazepine to reduce the duration of delirium in the ICU.

\section{Summary}

The adverse outcomes associated with delirium underscore the importance of the active screening, risk factor identification, preventive measures, and timely treatment of delirium symptoms in critically ill patients. Regarding ICU sedation, strategies that maintain a light level of sedation accompanying adequate analgesia are needed. It should also be emphasized that gradual dose decrement over several days is important to prevent withdrawal symptoms after prolonged use of high doses of various sedatives and opioids, although this was not mentioned above.

\section{References}

1. Liptzin B, Levkoff SE, Gottlieb GL, Johnson JC. Delirium. J Neuropsychiatry Clin Neurosci 1993; 5: 154-60.

2. Pandharipande P, Cotton BA, Shintani A, Thompson J, Costabile S, Truman Pun B, et al. Motoric subtypes of delirium in mechanically ventilated surgical and trauma intensive care unit patients. Intensive Care Med 2007; 33: 1726-31.

3. O'Keeffe ST. Clinical subtypes of delirium in the elderly. Dement Geriatr Cogn Disord 1999; 10: 380-5.

4. Peterson JF, Pun BT, Dittus RS, Thomason JW, Jackson JC, Shintani AK, et al. Delirium and its motoric subtypes: a study of 614 critically ill patients. J Am Geriatr Soc 2006; 54: 479-84.

5. O’Keeffe ST, Lavan JN. Clinical significance of delirium subtypes in older people. Age Ageing 1999; 28: 115-9.

6. Thomason JW, Shintani A, Peterson JF, Pun BT, Jackson JC, Ely EW. Intensive care unit delirium is an independent predictor of longer hospital stay: a prospective analysis of 260 nonventilated patients. Crit Care 2005; 9: R375-81.

7. Ely EW, Gautam S, Margolin R, Francis J, May L, Speroff T, et al. The impact of delirium in the intensive care unit on hospital length of stay. Intensive Care Med 2001; 27: 1892-900.

8. Ely EW, Shintani A, Truman B, Speroff T, Gordon SM, Harrell FE Jr, et al. Delirium as a predictor of mortality in mechanicall ventilated patients in the intensive care unit. JAMA 2004; 291: 1753-62.

9. Bowton DL. Delirium-the cost of inattention. Crit Care Med 2004; 32: 1080-1.

10. Milbrandt EB, Deppen S, Harrison PL, Shintani AK, Speroff T, Stiles RA, et al. Costs associated with delirium in mechanically ventilated patients. Crit Care Med 2004; 32: 955-62.

11. Jackson JC, Gordon SM, Hart RP, Hopkins RO, Ely EW. The association between delirium and cognitive decline: a review of the empirical literature. Neuropsychol Rev 2004; 14: 87-98.

12. van den Boogaard M, Schoonhoven L, Evers AW, van der Hoeven JG, van Achterberg T, Pickkers P. Delirium in critically ill patients: impact on long-term health-related quality of life and cognitive functioning. Crit Care Med 2012; 40: 112-8.

13. Shehabi Y, Riker RR, Bokesch PM, Wisemandle W, Shintani A, Ely EW. Delirium duration and mortality in lightly sedated, mechanically ventilated intensive care patients. Crit Care Med 2010; 38: 2311-8.

14. Lat I, McMillian W, Taylor S, Janzen JM, Papadopoulos S, Korth L, et al. The impact of delirium on clinical outcomes in mechanically ventilated surgical and trauma patients. Crit Care Med 2009; 37: 1898-905.

15. van den Boogaard M, Peters SA, van der Hoeven JG, Dagnelie PC, Leffers P, Pickkers P, et al. The impact of delirium on the prediction of inhospital mortality in intensive care patients. Crit Care 2010; 14: R146.

16. Treggiari MM, Romand JA, Yanez ND, Deem SA, Goldberg J, Hudson L, et al. Randomized trial of light versus deep sedation on mental health after critical illness. Crit Care Med 2009; 37: 2527-34.

17. Brook AD, Ahrens TS, Schaiff R, Prentice D, Sherman G, Shannon W, et al. Effect of a nursing-implemented sedation protocol on the duration of mechanical ventilation. Crit Care Med 1999; 27: 2609-15.

18. Kress JP, Pohlman AS, O’Connor MF, Hall JB. Daily interruption of sedative infusions in critically ill patients undergoing mechanical ventilation. N Engl J Med 2000; 342: 1471-7.

19. Kollef MH, Levy NT, Ahrens TS, Schaiff R, Prentice D, Sherman G. The use of continuous i.v. sedation is associated with prolongation of mechanical ventilation. Chest 1998; 114: 541-8. 
20. Girard TD, Kress JP, Fuchs BD, Thomason JW, Schweickert WD, Pun BT, et al. Efficacy and safety of a paired sedation and ventilator weaning protocol for mechanically ventilated patients in intensive care (Awakening and Breathing Controlled trial): a randomized controlled trial. Lancet 2008; 371: 126-34.

21. Devlin JW. The pharmacology of oversedation in mechanically ventilated adults. Curr Opin Crit Care 2008; 14: 403-7.

22. Foster J. Complications of sedation and critical illness. Crit Care Nurs Clin North Am 2005; 17: 287-96.

23. Shehabi Y, Chan L, Kadiman S, Alias A, Ismail WN, Tan MA, et al. Sedation depth and long-term mortality in mechanically ventilated critically ill adults: a prospective longitudinal multicentre cohort study. Intensive Care Med 2013; 39: 910-8.

24. Pandharipande P, Shintani A, Peterson J, Pun BT, Wilkinson GR, Dittus RS, et al. Lorazepam is an independent risk factor for transitioning to delirium in intensive care unit patients. Anesthesiology 2006; 104: 21-6.

25. Akça O, Melischek M, Scheck T, Hellwagner K, Arkiliç CF, Kurz A, et al. Postoperative pain and subcutaneous oxygen tension. Lancet 1999; 354: 41-2.

26. Hedderich R, Ness TJ. Analgesia for trauma and burns. Crit Care Clin 1999; 15: 167-84.

27. Beilin B, Shavit Y, Hart J, Mordashov B, Cohn S, Notti I, et al. Effects of anesthesia based on large versus small doses of fentanyl on natural killer cell cytotoxicity in the perioperative period. Anesth Analg 1996; 82: 492-7.

28. Pollock RE, Lotzová E, Stanford SD. Mechanism of surgical stress impairment of human perioperative natural killer cell cytotoxicity. Arch Surg 1991; 126: 338-42.

29. Peterson PK, Chao CC, Molitor T, Murtaugh M, Strgar F, Sharp BM. Stress and pathogenesis of infectious disease. Rev Infect Dis 1991; 13: 710-20.

30. Barr J, Fraser GL, Puntillo K, Ely EW, Gélinas C, Dasta JF, et al. Clinical practice guidelines for the management of pain, agitation, and delirium in adult patients in the intensive care unit. Crit Care Med 2013; 41: 263-306.

31. American psychiatric association. Diagnostic and statistical manual of mental disorders. 4th ed, Text revision. Washington, DC, American Psychiatric Publishing. 2000, pp135-42.

32. Ely EW, Inouye SK, Bernard GR, Gordon S, Francis J, May L, et al. Delirium in mechanically ventilated patients: validity and reliability of the confusion assessment method for the intensive care unit (CAM-ICU). JAMA 2001; 286: 2703-10.

33. Tsuruta R, Nakahara T, Miyauchi T, Kutsuna S, Ogino Y, Yamamoto T, et al. Prevalence and associated factors for delirium in critically ill patients at a Japanese intensive care unit. Gen Hosp Psychiatry 2010; 32: 607-11.

34. Sharma A, Malhotra S, Grover S, Jindal SK. Incidence, prevalence, risk factor and outcome of delirium in intensive care unit: a study from India. Gen Hosp Psychiatry 2012; 34: 639-46.

35. Van Rompaey B, Elseviers MM, Schuurmans MJ, Shortridge-Baggett LM, Truijen S, Bossaert L. Risk factors for delirium in intensive care patients: a prospective cohort study. Crit Care 2009; 13: R77.

36. Salluh JI, Soares M, Teles JM, Ceraso D, Raimondi N, Nava VS, et al. Delirium epidemiology in critical care (DECCA): an international study. Crit Care 2010; 14: R210.

37. McNicoll L, Pisani MA, Zhang Y, Ely EW, Siegel MD, Inouye SK, et al. Delirium in the intensive care unit: occurrence and clinical course in older patients. J Am Geriatr Soc 2003; 51: 591-8.

38. Pandharipande P, Cotton BA, Shintani A, Thompson J, Pun BT, Morris JA, et al. Prevalence and risk factors for development of delirium in surgical and trauma intensive care unit patients. J Trauma 2008; 65: 34-41.

39. Inouye SK. Delirium in older persons. N Engl J Med 2006; 354: 1157-65.

40. Ouimet S, Kavanagh BP, Gottfried SB, Skrobik Y. Incidence, risk factors and consequences of ICU delirium. Intensive Care Med 2007; 33 : 66-73.

41. Dubois MJ, Bergeron N, Dumont M, Dial S, Skrobik Y. Delirium in an intensive care unit: a study of risk factors. Intensive Care Med 2001; 27: 1297-304.

42. Marcantonio ER, Goldman L, Orav EJ, Cook EF, Lee TH. The association of intraoperative factors with the development of postoperative delirium. Am J Med 1998; 105: 380-4.

43. Litaker D, Locala J, Franco K, Bronson DL, Tannous Z. Preoperative risk factors for postoperative delirium. Gen Hosp Psychiatry 2001; 23: 84-9.

44. Devlin JW, Fong JJ, Fraser GL, Riker RR. Delirium assessment in the critically ill. Intensive Care Med 2007; 33: 929-40.

45. Ely EW, Margolin R, Francis J, May L, Truman B, Dittus R, et al. Evaluation of delirium in critically ill patients: validation of the Confusion Assessment Method for the Intensive Care Unit (CAM-ICU). Crit Care Med 2001; 29: 1370-9.

46. Inouye SK, van Dyck CH, Alessi CA, Balkin S, Siegal AP, Horwitz RI. Clarifying confusion: the confusion assessment method. A new method for detection of delirium. Ann Intern Med 1990; 113: 941-8.

47. Luetz A, Heymann A, Radtke FM, Chenitir C, Neuhaus U, Nachtigall I, et al. Different assessment tools for intensive care unit delirium: which score to use? Crit Care Med 2010; 38: 409-18.

48. van Eijk MM, den Boogaard M, van Marum RJ, Benner P, Eikelenboom P, Honing ML, et al. Routine use of the Confusion Assessment Method for the intensive care unit. Am J Respir Crit Care Med 2011; 184: 340-4.

49. Bergeron N, Dubois MJ, Dumont M, Dial S, Skrobik Y. Intensive Care Delirium Screening Checklist: evaluation of a new screening tool. Intensive Care Med 2001; 27: 859-64. 
50. Chanques G, Sebbane M, Barbotte E, Viel E, Eledjam JJ, Jaber S. A prospective study of pain at rest: incidence and characteristics of an unrecognized symptom in surgical and trauma versus medical intensive care unit patients. Anesthesiology 2007; 107: 858-60.

51. Payen JF, Chanques G, Mantz J, Hercule C, Auriant I, Leguillou JL, et al. Current practices in sedation and analgesia for mechanically ventilated critically ill patients: a prospective multicenter patient-based study. Anesthesiology 2007; 106: 687-95.

52. Pandharipande PP, Pun BT, Herr DL, Maze M, Girard TD, Miller RR, et al. Effect of sedation with dexmedetomidine vs lorazepam on acute brain dysfunction in mechanically ventilated patients: the MENDS randomized controlled trial. JAMA 2007; 298: 2644-53.

53. Riker RR, Shehabi Y, Bokesch PM, Ceraso D, Wisemandle W, Koura F, et al. Dexmedetomidine vs midazolam for sedation of critically ill patients: a randomized trial. JAMA 2009; 301: 489-99.

54. Pisani MA, Murphy TE, Araujo KL, Slattum P, Van Ness PH, Inouye SK. Benzodiazepine and opioid use and the duration of intensive care unit delirium in an older population. Crit Care Med 2009; 37: 177-83.

55. Marcantonio ER, Juarez G, Goldman L, Mangione CM, Ludwig LE, Lind L, et al. The relationship of postoperative delirium with psychoactive medications. JAMA 1994; 272: 1518-22.

56. Skrobik Y, Ahern S, Leblanc M, Marquis F, Awissi DK, Kavanagh BP. Protocolized intensive care unit management of analgesia, sedation, and delirium improves analgesia and subsyndromal delirium rates. Anesth Analg 2010; 111: 451-63.

57. Mehta S, Burry L, Cook D, Fergusson D, Steinberg M, Granton J, et al. Daily sedation interruption in mechanically ventilated critically ill patients cared for with a sedation protocol: a randomized controlled trial. JAMA 2012; 308: 1985-92.

58. Arabi Y, Haddad S, Hawes R, Moore T, Pillay M, Naidu B, et al. Changing sedation practices in the intensive care unit-Protocol implementation, multifaceted mulitidisciplinary approach and teamwork. Middle East J Anesthesiol 2007; 19: 429-47.

59. Arias-Rivera S, Sánchez-Sánchez Mdel M, Santos-Díaz R, Gallardo-Murillo J, Sánchez-Izquierdo R, Frutos-Vivar F, et al. Effect of a nursingimplemented sedation protocol on weaning outcome. Crit Care Med 2008; 36: 2054-60.

60. Brattebø G, Hofoss D, Flaatten H, Muri AK, Gjerde S, Plsek PE. Effect of a scoring system and protocol for sedation on duration of patients' need for ventilator support in a surgical intensive care unit. BMJ 2002; 324: 1386-9.

61. Quenot JP, Ladoire S, Devoucoux F, Doise JM, Cailliod R, Cunin N, et al. Effect of a nurse-implemented sedation protocol on the incidence of ventilator-associated pneumonia. Crit Care Med 2007; 35: 2031-6.

62. Robinson BR, Mueller EW, Henson K, Branson RD, Barsoum S, Tsuei BJ. An analgesia-delirium-sedation protocol for critically ill trauma patients reduces ventilator days and hospital length of stay. J Trauma 2008; 65: 517-26.

63. Bucknall TK, Manias E, Presneill JJ. A randomized trial of protocol-directed sedation management for mechanical ventilation in an Australian intensive care unit. Crit Care Med 2008; 36: 1444-50.

64. Elliott R, McKinley S, Aitken LM, Hendrikz J. The effect of an algorithm-based sedation guideline on the duration of mechanical ventilation in an Australian intensive care unit. Intensive Care Med 2006; 32: 1506-14.

65. Mascia MF, Koch M, Medicis JJ. Pharmacoeconomic impact of rational use guidelines on the provision of analgesia, sedation, and neuromuscular blockade in critical care. Crit Care Med 2000; 28: 2300-6.

66. Marshall J, Finn CA, Theodore AC. Impact of a clinical pharmacist-enforced intensive care unit sedation protocol on duration of mechanical ventilation and hospital stay. Crit Care Med 2008; 36: 427-33.

67. DuBose JJ, Inaba K, Shiflett A, Trankiem C, Teixeira PG, Salim A, et al. Measurable outcomes of quality improvement in the trauma intensive care unit: the impact of a daily quality rounding checklist. J Trauma 2008; 64: 22-7.

68. Devlin JW, Holbrook AM, Fuller HD. The effect of ICU sedation guidelines and pharmacist interventions on clinical outcomes and drug cost. Ann Pharmacother 1997; 31: 689-95.

69. Muellejans B, Matthey T, Scholpp J, Schill M. Sedation in the intensive care unit with remifentanil/propofol versus midazolam/fentanyl: a randomised, open-label, pharmacoeconomic trial. Crit Care 2006; 10: R91.

70. Breen D, Karabinis A, Malbrain M, Morais R, Albrecht S, Jarnvig IL, et al. Decreased duration of mechanical ventilation when comparing analgesia-based sedation using remifentanil with standard hypnotic-based sedation for up to 10 days in intensive care unit patients: a randomised trial (ISRCTN47583497). Crit Care 2005; 9: R200-10.

71. Rozendaal FW, Spronk PE, Snellen FF, Schoen A, van Zanten AR, Foudraine NA, et al. Remifentanil-propofol analgo-sedation shortens duration of ventilation and length of ICU stay compared to a conventional regimen: a centre randomised, cross-over, open-label study in the Netherlands. Intensive Care Med 2009; 35: 291-8.

72. Pandharipande PP, Sanders RD, Girard TD, McGrane S, Thompson JL, Shintani AK, et al. Effect of dexmedetomidine versus lorazepam on outcome in patients with sepsis: an a priori-designed analysis of the MENDS randomized controlled trial. Crit Care 2010; 14 : R38.

73. Esmaoglu A, Ulgey A, Akin A, Boyaci A. Comparison between dexmedetomidine and midazolam for sedation of eclampsia patients in the intensive care unit. J Crit Care 2009; 24: 551-5.

74. Jakob SM, Ruokonen E, Grounds RM, Sarapohja T, Garratt C, Pocock SJ, et al. Dexmedetomidine vs midazolam or propofol for sedation during prolonged mechanical ventilation: two randomized controlled trials. JAMA 2012; 307: 1151-60.

75. Carson SS, Kress JP, Rodgers JE, Vinayak A, Campbell-Bright S, Levitt J, et al. A randomized trial of intermittent lorazepam versus propofol with daily interruption in mechanically ventilated patients. Crit Care Med 2006; 34: 1326-32.

76. Ho KM, Ng JY. The use of propofol for medium and long-term sedation in critically ill adult patients: a meta-analysis. Intensive Care Med 2008; 34: 1969-79. 
77. Vidán MT, Sánchez E, Alonso M, Montero B, Ortiz J, Serra JA. An intervention integrated into daily clinical practice reduces the incidence of delirium during hospitalization in elderly patients. J Am Geriatr Soc 2009; 57: 2029-36.

78. Inouye SK, Bogardus ST Jr, Charpentier PA, Leo-Summers L, Acampora D, Holford TR, et al. A multicomponent intervention to prevent delirium in hospitalized older patients. N Engl J Med 1999; 340: 669-76.

79. Colombo R, Corona A, Praga F, Minari C, Giannotti C, Castelli A, et al. A reorientation strategy for reducing delirium in the critically ill. Results of an interventional study. Minerva Anestesiol 2012; 78: 1026-33.

80. Schweickert WD, Pohlman MC, Pohlman AS, Nigos C, Pawlik AJ, Esbrook CL, et al. Early physical and occupational therapy in mechanically ventilated, critically ill patients: a randomised controlled trial. Lancet 2009; 373: 1874-82.

81. Needham DM, Korupolu R, Zanni JM, Pradhan P, Colantuoni E, Palmer JB, et al. Early physical medicine and rehabilitation for patients with acute respiratory failure: a quality improvement project. Arch Phys Med Rehabil 2010; 91: 536-42.

82. Vasilevskis EE, Ely EW, Speroff T, Pun BT, Boehm L, Dittus RS. Reducing iatrogenic risks: ICU-acquired delirium and weakness-crossing the quality chasm. Chest 2010; 138: 1224-33.

83. Morandi A, Brummel NE, Ely EW. Sedation, delirium and mechanical ventilation. The 'ABCDE' approach. Curr Opin Crit Care 2011; 17: 43-9.

84. Pandharipande P, Banerjee A, McGrane S, Ely EW. Liberation and animation for ventilated ICU patients: the ABCDE bundle for the backend of critical care. Crit Care 2010; 14: 157.

85. Wang W, Li HL, Wang DX, Zhu X, Li SL, Yao GQ, et al. Haloperidol prophylaxis decreases delirium incidence in elderly patients after noncardiac surgery: a randomized controlled trial. Crit Care Med 2012; 40: 731-9.

86. Prakanrattana U, Prapaitrakool S. Efficacy of risperidone for prevention of postoperative delirium in cardiac surgery. Anaesth Intensive Care 2007; 35: 714-9.

87. Jacobi J, Fraser GL, Coursin DB, Riker RR, Fontaine D, Wittbrodt ET, et al. Clinical practice guidelines for the sustained use of sedatives and analgesics in the critically ill adult. Crit Care Med 2002; 30: 119-41.

88. Kosten TR, O’Conner PG. Management of drug and alcohol withdrawal. N Engl J Med 2003; 348: 1786-95.

89. Rea RS, Battistone S, Fong JJ, Devlin JW. Atypical antipsychotics versus haloperidol for treatment of delirium in acutely ill patients. Pharmacotherapy 2007; 27: 588-94.

90. Ozbolt LB, Paniagua MA, Kaiser RM. Atypical antipsychotics for the treatment of delirious elders. Am Med Dir Assoc 2008; 9: $18-28$.

91. Hunt N, Stern TA. The association between intravenous haloperidol and Torsades de Pointes. Three cases and a literature review. Psychosomatics 1995; 36: 541-9.

92. Sharma ND, Rosman HS, Padhi ID, Tisdale JE. Torsades de Pointes associated with intravenous haloperidol in critically ill patients. Am J Cardiol 1998; 81: 238-40.

93. Muzyk AJ, Rayfield A, Revollo JY, Heinz H, Gagliardi JP. Examination of baseline risk factors for QTc interval prolongation in patients prescribed intravenous haloperidol. Drug Saf 2012; 35: 547-53.

94. Jolly K, Gammage MD, Cheng KK, Bradburn P, Banting MV, Langman MJ. Sudden death in patients receiving drugs tending to prolong the QT interval. Br J Clin Pharmacol 2009; 68: 743-51.

95. Meyer-Massetti C, Vaerini S, Rätz Bravo AE, Meier CR, Guglielmo BJ. Comparative safety of antipsychotics in the WHO pharmacovigilance database: the haloperidol case. Int J Clin Pharm 2011; 33: 806-14.

96. Heinrich TW, Biblo LA, Schneider J. Torsades de pointes associated with ziprasidone. Psychosomatics 2006; 47: 264-8. 